\title{
Primeros eslabones de la criminalización a mujeres: detención policial a mujeres en la Comunidad Autónoma de Euskadi (CAE) (First Steps in the Criminalization of Women: Police Detention of Women in the Basque Autonomous Community)
}

\author{
OÑATI SOCIO-LEGAL SERIES VOLUME 10, ISSUE 2 (2020): El GÉNERO DE LOS SISTEMAS PENALES \\ JUVENILES: DEBATES NECESARIOS \\ DOI LINK: HTTPS://DOI.ORG/10.35295/OSLS.IISL/0000-0000-0000-1071 \\ RECEIVED 26 MARCH 2019, ACCEPTED 18 JULY 2019
}

\author{
Estibaliz de Miguel CALVO* (D) \\ LOHITZUNE ZULOAGA LOJO* id
}

\section{Resumen}

El presente artículo describe, desde una perspectiva de género, la experiencia de la detención policial a mujeres en la Comunidad Autónoma de Euskadi durante el periodo 2011-2016. Nos centramos en los perfiles sociodemográficos las de mujeres imputadas o detenidas y en el grado de cumplimiento de los derechos que les asisten durante la detención. Para ello, se han estudiado las estadísticas policiales disponibles por la Ertzaintza, complementadas con datos de las principales policías locales, y se ha trabajado con información cualitativa procedente de 62 entrevistas semiestructuradas

\footnotetext{
Agradecemos a Miren Ortubay Fuentes su valiosa aportación en el capítulo 2 de este artículo donde se describe el marco jurídico e institucional de la detención policial.

Investigación financiada por Emakunde-Instituto Vasco de la Mujer. Beca 2. 2016/2017.

* Profesora en el departamento de Sociología II, UPV/EHU. Doctora en Sociología y diplomada en Trabajo Social. Premio Micaela Portilla (UPV/EHU) a la mejor tesis feminista/de género 2012. 2º Accésit en el IX Premio Fermín Caballero de Ensayo en Ciencias Sociales. Últimas publicaciones: (2017): “Explorando la agencia de las mujeres encarceladas a través de sus experiencias amorosas". Papers. Revista de Sociología vol. 102, no 2.; (2016): "Mujeres, consumo de drogas y encarcelamiento. Una aproximación interseccional”. Política y Sociedad, vol. 53, no2. (2016): "Relaciones amorosas de las mujeres encarceladas". Leioa: Universidad del País Vasco. Servicio Editorial; (2015): “Mujeres consumidoras de drogas en prisión” en Praxis Sociológica, $\mathrm{n}^{\mathrm{o}}$ 19, pp. 141-159. Áreas de investigación: sistema penal y género, encarcelamiento de mujeres, estratificación social, amor y emociones. Datos de contacto: UPV/EHU. Departamento de Sociología II. Facultad de Ciencias Sociales y de la Comunicación. Barrio Sarriena s/n. 48970. Leioa. Bizkaia. Dirección de email: estibaliz.demiguel@ehu.eus

* Profesora en el departamento de Sociología y Trabajo Social, UPNA. Doctora en Sociología. Miembro del instituto de investigación I-Communitas. Últimas publicaciones: (2018): “Áreas de estudio de la sociología del crimen", en Introducción a la sociología del crimen. Madrid: Delta; (2016): “La concepción securitaria de la inmigración en el caso español", en Athenea Digital, 16 (2), pp. 215-244; (2014): El espejismo de la seguridad ciudadana. Claves de su presencia en la agenda política. Madrid: Catarata; (2015): "La Violencia de Género en la Agenda mediática: El caso de la Ley Integral de Violencia de Género (LO 1/2004)”, Oñati Socio-Legal Series, 5 (2), pp. 804-821. Datos de contacto: UPNA. Departamento de Sociología y Trabajo Social. Campus de Arrosadía s/n. 31006. Pamplona. Navarra. Dirección de email: lohitzune.zuloaga@unavarra.es
} 
que recogen la voz de las protagonistas y la mirada de diferentes agentes implicados: policías, abogacía y entidades sociales. Los resultados muestran que entre las imputadas y detenidas existe una sobrerrepresentación de extranjeras y de mujeres pertenecientes a grupos atravesados por varios ejes de desigualdad. Los derechos durante la detención son respetados, salvo algunos elementos a considerar en su forma de aplicación, sobre todo en casos de perfiles no-hegemónicos.

\section{Palabras clave}

Sistema penal; criminalización de mujeres; policía; género; interseccionalidad

\section{Abstract}

This article describes, from a gender perspective, the experiences of police detention of women in the Autonomous Community of Euskadi during the 2011-2016 period. We focus on socio-demographic profiles of women suspected of a crime and the degree of compliance with the rights that assist them during detention. For this, the police statistics available by the Ertzaintza-Basque Autonomous Police, complemented with data provided by the main local police, were analyzed as well as qualitative information produced through 62 semi-structured interviews that raise the voice of the protagonists and the view of different agents involved: police officers, lawyers, and social movements. The results show that among the accused and detainees, there is an overrepresentation of foreigners and women belonging to groups crossed by several axes of inequality. Their rights during detention are respected, except for some elements to consider in their application, especially in the case of non-hegemonic profiles.

\section{Key words}

Penal system; criminalization of women; police; gender; intersectionality 


\section{Índice/Table of contents}

1. Introducción 468

2. Marco jurídico e institucional de la detención policial ..... 472

2.1. Concepto, presupuestos y duración de la detención 472

2.2. Desarrollo de la detención: los derechos de la persona detenida 473

2.3. El contexto institucional: la policía en la Comunidad Autónoma de Euskadi 475 3. La presencia de las mujeres en las estadísticas policiales y sus perfiles sociodemográficos 476

3.1. Número de mujeres en las estadísticas policiales vascas. 476

3.2. Delitos objeto de detención e imputación a mujeres en la CAE............................477

3.3. Perfiles de las mujeres detenidas en la CAE ....................................................... 478

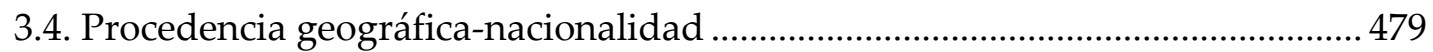

4. El proceso de la detención. Cumplimiento de derechos formales, con matices......... 479

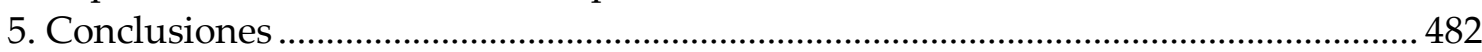

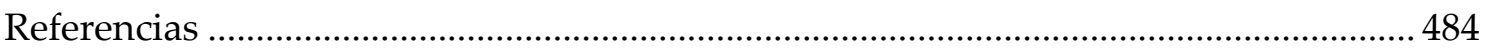

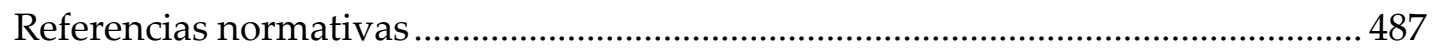




\section{Introducción}

En este artículo se presentan los resultados de la investigación sociológica sobre la experiencia de la detención policial a mujeres en la Comunidad Autónoma de Euskadi (CAE). ${ }^{1}$ Concretamente, el trabajo ha estudiado los siguientes dos aspectos: por un lado, los perfiles y problemáticas de las mujeres imputadas por la policía, sean o no detenidas; y, por otro, el grado de cumplimiento de los derechos de las personas detenidas, así como las dificultades de implementación de dichos derechos en casos de personas con perfiles que no corresponden a los grupos sociales hegemónicos (cis género masculino, etnia o raza blanca, situación administrativa legal, nacionalidad autóctona, hablante de lengua mayoritaria, etc.).

El proyecto nace de la inquietud al observar que las investigaciones realizadas desde la criminología y la sociología jurídica se centran, sobre todo, en el estudio del carácter criminalizador de las políticas públicas (Zuloaga 2014, Díez Ripollés 2015, Antón-Mellón y Antón 2017) y en sus consecuencias, como es el espacio de la prisión. Los estudios sociales con perspectiva de género disponibles se han preocupado principalmente de las sentencias firmes de mujeres condenadas, prestando especial atención a ese porcentaje menor del $10 \%$ que suponen las mujeres entre la población encarcelada a nivel mundial (Walmsley 2015).

Poco se ha analizado ese estadio intermedio que es el ámbito policial. Nuestra investigación se dirige a analizar este espacio para averiguar qué ocurre con las mujeres que transitan por las comisarías de policía acusadas de cometer alguna infracción. Nos interesa conocer cuál es su condición de detenidas y su vivencia como mujeres, que puede estar afectada, además, por diferentes ejes de desigualdad social. Nos centramos en analizar un eslabón dentro de lo que se ha venido a denominar "proceso de selección penal". Partimos de la base de que existe una divergencia entre los delitos que se cometen cotidianamente y aquellos por los que ciertas personas son encarceladas (Sutherland 1999); así como entre los delitos detectados por la policía y aquellos que son sentenciados y por los que las personas son enviadas a prisión (Manzanos 1991), tal y como vienen poniendo de manifiesto las teorías críticas de la criminalidad desde los años 70, desplazando así el interés de la disciplina "desde las causas del comportamiento criminal hacia los mecanismos sociales e institucionales mediante los cuales se elabora la "realidad social" de la desviación" (Maqueda 2014, p. 102).

Precisamente, las investigaciones sobre la realidad de las mujeres encarceladas han puesto de manifiesto la sobrerrepresentación de aquellas que se ven atravesadas por varios ejes de desigualdad, como son las mujeres extranjeras, ya sean migrantes o no nacionales sin proyecto migratorio (Ribas y Martínez 2003, Martín-Palomo et al. 2005, Ribas et al. 2005, Miranda y Martín-Palomo 2007), gitanas (Equipo Barañí 2001, Imaz y Martín-Palomo 2007), o consumidoras de drogas con patrones exclusógenos (Gañan y Gordon 2001, Markez y Silvosa 2012, Almeda et al. 2012, De Miguel Calvo 2016). Los enfoques críticos de la realidad penitenciaria con perspectiva de género han mostrado

\footnotetext{
${ }^{1}$ La investigación ha sido financiada por Emakunde-Instituto Vasco de la Mujer, a través de una beca tipo B encaminada al estudio de "las situaciones y de las desigualdades en los colectivos de mujeres en riesgo de discriminación múltiple, especialmente en el acceso a los recursos sociales, económicos y en la seguridad", tal y como consta en sus bases (Emakunde 2015). Fue llevada a cabo por Lohitzune Zuloaga (coordinadora), Estibaliz de Miguel y Miren Ortubay, con la inestimable ayuda de Natacha Guala e Itziar Gandarias.
} 
que la mayoría de mujeres encarceladas han padecido exclusión primaria previa al ingreso en prisión, es decir, alguna situación de vulnerabilidad o exclusión social (Cruells y Torrens 2004).

De esta manera, identificamos que el control social formal y la selección penal no tienen únicamente un marcado carácter de clase social, persiguiendo y castigando a aquellas personas de estratos sociales bajos o de grupos estigmatizados socialmente, sino también de género y otros ejes de desigualdad social. A este respecto, la criminología feminista y la sociología jurídica con perspectiva de género han subrayado que las trayectorias y circunstancias que llevan a las mujeres a cometer delitos son cualitativamente diferentes a las de los hombres (Heimer y Kruttschnitt 2005), dando así visibilidad a las mujeres en los estudios sobre delincuencia y ofreciendo una alternativa a la persistencia de perspectivas androcéntricas y ciegas al género en la disciplina (Smart 1977, Gelsthorpe y Morris 1990).

Desde esta perspectiva, ambas estructuras (capitalismo y patriarcado, clase social y género) no operan siempre de modo análogo (Larrauri 1992) y, por tanto, no pueden equipararse sin introducir transformaciones en el marco analítico. Este cambio de perspectiva ha conducido a las estudiosas feministas de este campo a prestar atención a cuestiones que afectan específicamente a las mujeres, como son el miedo a la violencia, la sexualidad, o la ideología que asigna un determinado papel a la mujer en la sociedad; y a interpretarlos como "mecanismos de control peculiares, dirigidos a las mujeres" (Larrauri 1992, p. 194). A este respecto, Restrepo y Francés (2016) ponen el acento en la íntima relación entre patriarcado y poder punitivo, al evidenciar que el sistema de opresión, de castigo, presenta características esenciales del poder patriarcal, pues nace de y para él.

Considerando la progresiva ampliación del objeto de estudio de la criminología feminista, actualmente pueden distinguirse varias áreas de trabajo (Beltrán 2010), de las cuales aquí nos interesan dos especialmente: la descripción de patrones de delincuencia de mujeres y jóvenes (tipo de infracciones, sentencias, arrestos, motivos que las llevan a infringir la ley, etc.); y el tratamiento del sistema de justicia a las mujeres infractoras, que incluye el estudio del funcionamiento de las instituciones y las expectativas sobre el comportamiento esperado en las mujeres, especialmente en el terreno de la sexualidad y de las relaciones familiares. ${ }^{2}$

En el contexto del Estado español, las investigaciones y políticas implementadas hasta el momento en lo referente a la práctica policial se han centrado predominantemente en la forma como se atiende a mujeres víctimas de violencia de género (Blay Gil 2013). Encontramos incluso trabajos particularmente relevantes orientados a conocer esta situación en el territorio vasco (Argituz 2012, Dirección de Atención a las Víctimas de Violencia de Género -DAVVG- 2012). Pero es prácticamente nula la atención dedicada a la situación en comisaría de mujeres potencialmente delincuentes, más allá de casos flagrantes de violación de derechos humanos, como la tortura o la situación de

\footnotetext{
${ }^{2}$ Las otras áreas de trabajo que menciona Beltrán son: presencia de las mujeres en las pandillas callejeras; imagen de las mujeres delincuentes en los medios de comunicación; y violencia de género en la pareja y el uso diferenciado de la violencia en el caso de hombres y mujeres.
} 
incomunicación (Etxeberria et al. 2016, Comité para la Prevención de la Tortura 2017, Draminsky Petersen y Morentin 2017).

Canteras (1990) dedicó en su momento un apartado de su análisis sobre la delincuencia femenina en España a las estadísticas disponibles por parte del Cuerpo Nacional de Policía y de la Guardia Civil. Poco más parece haberse adentrado la criminología española en estos terrenos desde entonces, a la vista de las publicaciones en las revistas científicas más importantes de este campo. Tampoco en la Comunidad Autónoma de Euskadi (CAE) parecen haberse realizado estudios empíricos en este ámbito, por lo que se deduce de la revisión de publicaciones de organismos especializados. La ausencia no se refiere únicamente a la falta de un análisis de datos oficiales de detenciones e identificación de delitos por parte de la policía y su desagregación por sexo, sino también a aspectos referidos a los perfiles de las mujeres detenidas, sus circunstancias personales y familiares, y la perspectiva del personal policial en la toma de determinadas decisiones.

Los principales organismos internacionales han expresado la necesidad de estudiar y analizar la situación penal de las personas desde una perspectiva de género. En el año 2000 se firmó la Declaración de Viena sobre la Delincuencia y la Justicia (2000), en la que los estados miembros de las Naciones Unidas se comprometieron a formular recomendaciones de políticas públicas orientadas a la acción y basadas en las necesidades especiales de las mujeres en su calidad de reclusa o delincuente. Una década más tarde, las Reglas de las Naciones Unidas para el tratamiento de las reclusas y medidas no privativas de la libertad para las mujeres delincuentes (Reglas de Bangkok, 2011) invitaron a los estados miembros a que "reúnan, mantengan, analicen y publiquen datos concretos sobre las reclusas y las delincuentes".

De manera similar a lo comentado sobre el eje analítico de género en la perspectiva crítica, contar con el eje grupo étnico y otros ejes de desigualdad y diversidad entre mujeres cambia el análisis, de forma que éste no puede basarse exclusivamente en la opresión patriarcal, ya que esta opresión tiene efectos muy diferentes en función de las diversas posiciones de las mujeres. Por tanto, resulta necesario desarrollar una perspectiva situacional e interactiva, que permita contemplar cómo los ejes de clase, género, etnia y cultura (y otros) interactúan de forma compleja (Rice 1990). Una perspectiva interseccional en los estudios de género (Combahee River Collective 2012, Crenshaw 2012, Platero 2014, Gandarias 2017) en relación a las mujeres criminalizadas (De Miguel Calvo 2016) resulta particularmente útil a nuestros objetivos de investigación orientados a apreciar los perfiles y problemáticas diferentes de las mujeres infractoras: pobreza, extranjería, consumo de drogas, etc. Por tanto, la estratificación social no se articula en base a un solo eje de desigualdad, sino a través de múltiples dimensiones donde, además del género, la clase social y la raza juegan un papel crucial (Bottero 2005).

Esta forma interseccional de analizar la realidad permite identificar los diferentes condicionantes que las constriñen y el papel que tienen las agencias de control social formal en el abundamiento de estas desigualdades. Chesney-Lind (2006), precisamente, revisando la situación actual de la criminología feminista y los retos que se le presentan, defiende la necesidad de priorizar el estudio de los nexos entre diferentes variables que confluyen en las políticas de castigo. Esto supone, nuevamente, ampliar el marco de interpretación y reconceptualizar nociones básicas de la criminología feminista y la sociología del delito con perspectiva de género. La atención sobre el eje de género ha 
estado necesariamente acompañada de la identificación de otras situaciones de desigualdad, que se solapan y que explican de manera más precisa la situación y vivencia de las personas que, además de ser mujeres, pertenecen a una clase social, etnia o raza no hegemónicas, o hablan una lengua extranjera o minoritaria. Esto ejes se han contemplado en las estadísticas analizadas, en la medida que estas recogían las variables, pero sobre todo han sido a través de las entrevistas con los diversos agentes donde se ha podido interrogar acerca de las diferencias que estas variables generaban en la experiencia de la detención policial, tal y como se detallará en el apartado de análisis de resultados.

Hemos seleccionado el periodo 2011-2016 para conocer las experiencias y los hechos más recientes acontecidos en la Comunidad Autónoma de Euskadi (CAE) en lo referente a los perfiles de las mujeres detenidas, sus circunstancias de detención en dependencias policiales, las condiciones de estancia en dichas dependencias, así como las dinámicas de la intervención policial para, finalmente, recoger buenas prácticas y establecer recomendaciones de mejora en la atención a mujeres durante la detención.

Para lograr los objetivos propuestos, la obtención y análisis de datos se ha basado en la combinación flexible tanto de técnicas cualitativas como de técnicas cuantitativas. Por un lado, la explotación de microdatos de estadísticas policiales ha permitido obtener información cuantitativa relativa al perfil sociodemográfico de las mujeres detenidas en la CAE. Las fuentes de información de referencia han sido las estadísticas policiales remitidas por la Ertzaintza y por las principales policías locales en número de habitantes, previa petición formal a las administraciones competentes con el objetivo específico de ejecutar la presente investigación. La ausencia de un registro centralizado de datos alimentado por las policías locales de los diferentes municipios de la CAE nos obligó a seleccionar los más importantes para solicitarles estadísticas detalladas y de utilidad para nuestra investigación. Por ello, las policías locales a las que se les pidió información han sido: Bilbao, Donostia-San Sebastián, Vitoria-Gasteiz, Irún, Durango y Laudio/Llodio. Éstas representan a los dos principales municipios en número de habitantes de cada territorio histórico, aunque en el caso de Bizkaia optamos por elegir el primer municipio que no formara parte del Gran Bilbao y poder así, en la medida de lo posible, representar espacios no tan urbanizados como con las tres capitales. Considerando el tiempo disponible y los procedimientos necesarios para lograr estadísticas desagregadas por sexo recogidas por el Cuerpo Nacional de Policía (CNP) y por la Guardia Civil, resolvimos renunciar en esta ocasión a los datos procedentes de los dos cuerpos con menor presencia en la CAE.

La información cualitativa se ha construido en base a entrevistas semiestructuradas que aportan conocimiento en referencia a los significados, interpretaciones y vivencias relacionadas con la detención policial a mujeres. Concretamente, se han realizado un total de 62 entrevistas, que podemos dividir en los siguientes bloques: 9 entrevistas a mujeres acusadas de haber cometido algún tipo de infracción penal, 32 entrevistas a agentes policiales, 11 entrevistas a personas que ejercen la abogacía, y 10 entrevistas a entidades sociales/asociaciones civiles que trabajan en distintos contextos y que están en relación con personas que han entrado en contacto con el sistema penal.

En el siguiente apartado describimos el marco legal de la detención policial, para pasar a continuación a apuntar los rasgos del contexto de la CAE en lo que se refiere a las 
fuerzas policiales. Los dos apartados posteriores presentan resultados de la investigación en referencia a las dos cuestiones que nos atañen en este texto: los perfiles de las mujeres imputadas y detenidas, y el cumplimiento de derechos durante la situación de detención.

\section{Marco jurídico e institucional de la detención policial}

La detención constituye un momento crítico en el inicio del proceso penal, sobre todo porque supone una injerencia muy drástica en los derechos fundamentales de quien la sufre. Detallamos a continuación el significado jurídico de este concepto, los presupuestos que lo sustentan y las referencias que la ley hace sobre la duración máxima de la misma.

\subsection{Concepto, presupuestos y duración de la detención}

La detención es una privación de libertad que se realiza -en los supuestos previstos por la ley- con la finalidad de poner a una persona a disposición judicial. No se trata de una medida punitiva, puesto que no pretende «castigar», sino que es una medida cautelar que busca garantizar la efectividad del proceso penal y de las decisiones judiciales. A pesar de ello, resulta evidente que la detención supone la negación del derecho fundamental a la libertad de movimientos (Constitución Española-CE-, 1978, art. 17) y, precisamente por eso, solo puede acordarse en los supuestos previstos legalmente (Ley Orgánica 13/2015 de Enjuiciamiento Criminal -LECrim- arts. 490 y 492) y cuando sea imprescindible, es decir, cuando no haya otra medida cautelar menos lesiva para los derechos de la persona afectada y de eficacia semejante. En determinadas circunstancias, la detención puede ser "incomunicada", lo que implica una mayor restricción de los derechos de la persona detenida.

A diferencia de lo que ocurre con la mayoría de las restricciones de derechos fundamentales, la detención no tiene por qué ser una decisión judicial, sino que normalmente la acuerdan las fuerzas policiales e, incluso, puede ser realizada por particulares en determinadas circunstancias. Frente a esa autorización -bastante excepcional- que se otorga a cualquiera de detener al delincuente in fraganti o a quien se halle en "busca y captura", la ley establece el deber de los agentes de la policía judicial de proceder a la detención en dichos supuestos, a los que añade algunos otros:

La Autoridad o agente de Policía judicial tendrá obligación de detener: (...)

3. Al procesado por delito (...), si sus antecedentes o las circunstancias del hecho hicieren presumir que no comparecerá cuando fuere llamado por la Autoridad judicial.

4. Al que estuviere en el caso del número anterior, aunque todavía no se hallase procesado, con tal que concurran las dos circunstancias siguientes: 1. ․ Que la Autoridad o agente tenga motivos racionalmente bastantes para creer en la existencia de un hecho que presente los caracteres de delito. $2^{a}$. Que los tenga también bastantes para creer que la persona a quien intente detener tuvo participación en él.

Esta actuación policial, que es la que, en el lenguaje habitual, se identifica con la detención, se basa por tanto en una imputación -todavía no formalizada- de unos hechos delictivos a una persona (Armenta 2010, p. 166). Conviene realizar dos precisiones. 
Por un lado, no se puede detener por falta, salvo que la persona sospechosa de haberla cometido "no tuviese domicilio conocido ni diese fianza bastante" (LECrim, art. 495). Esta excepción tiene bastante importancia en la práctica, porque se aplica con frecuencia a inmigrantes en situación administrativa irregular $-\mathrm{e}$, incluso, con permiso de residencia-, lo que incrementa su presencia en las estadísticas de detenciones.

El texto del mencionado artículo se ha mantenido a pesar de que la reforma del Código Penal de 2015 ha eliminado las faltas, despenalizando las conductas en algunos -pocoscasos y convirtiendo la mayoría en "delitos leves". Si se atiende sólo a la letra de la ley, habría que concluir que se han incrementado notablemente las facultades policiales para detener -por ejemplo, ahora cabría hacerlo por un hurto de $50 €-$, aunque no es seguro que esa fuese la finalidad del legislador, ¿o quizás sí? No es este el lugar adecuado para esta reflexión, pero resulta evidente que también en este aspecto la precipitada e infundada reforma de 2015 ha generado una grave inseguridad jurídica, que perjudica tanto a agentes policiales como a las personas afectadas por sus decisiones.

Por otro lado, la privación de libertad que la detención implica tiene que resultar estrictamente necesaria para garantizar la posterior actuación judicial. Por ello, el citado artículo 492.3º, tras exigir que de las circunstancias del hecho (en particular, la gravedad del delito) o del sujeto (antecedentes) hagan prever que no va a presentarse en el juzgado, añade que, aun en tal caso, no se procederá a la detención si la persona sospechosa presta "fianza bastante, a juicio de la Autoridad o agente que intente detenerlo, para presumir racionalmente que comparecerá".

En conclusión, la detención es una medida muy restrictiva de derechos, por lo que debe ser excepcional. De hecho, la norma general es la establecida en el art. 486 LECrim, según el cual "la persona a quien se le impute un acto punible deberá ser citada sólo para ser oída".

Por lo que se refiere a la duración de la detención, las leyes establecen unos límites temporales que deben respetarse estrictamente, puesto que -como se ha reiteradoimplica una grave restricción del derecho de libertad ambulatoria. En este sentido, el artículo 17.2 de la Constitución señala que "la detención preventiva no podrá durar más del tiempo estrictamente necesario para la realización de las averiguaciones tendentes al esclarecimiento de los hechos, y, en todo caso, en el plazo máximo de setenta y dos horas, el detenido deberá ser puesto en libertad o a disposición de la autoridad judicial". Por su parte, también el art. 520 LECrim insiste en las dos notas esenciales contenidas en el precepto constitucional, de manera que, si se supera ese tiempo "mínimo imprescindible", definido por la complejidad del delito y de las dificultades para su esclarecimiento, podría incurrirse en una detención ilegal, aunque no se superase el límite de las 72 horas (Segovia 2011, p. 28).

\subsection{Desarrollo de la detención: los derechos de la persona detenida}

Puesto que, como hemos dicho, la detención supone una negación del derecho fundamental a moverse libremente, debe regularse legalmente no sólo sobre quién, cómo y cuándo puede realizarla, sino también sobre las condiciones en las que ha de desarrollarse. Así, la ley establece unas garantías mínimas, que constituyen unos derechos subjetivos -es decir, exigibles- de la persona. Si tales derechos no se respetan, la detención se convierte en ilegal y, por tanto, constituye un delito, lo que genera la 
posibilidad de que la persona afectada solicite un Habeas Corpus (Segovia 2011, p. 45 y ss.).

El art. 520 LECrim, que regula esta delicada materia, comienza aludiendo al necesario respeto a los derechos derivados de la dignidad de la persona detenida (honor, intimidad e imagen), por lo que ordena que la detención se practique "en la forma que menos perjudique al detenido (...) en su persona, reputación y patrimonio".

La información constituye un principio básico, que condiciona el ejercicio del resto de los derechos. Para asegurarla, el art. 520 LECrim establece que toda persona detenida "será informada por escrito, en un lenguaje sencillo y accesible, en una lengua que comprenda y de forma inmediata, de los hechos que se le atribuyan y las razones motivadoras de su privación de libertad, así como de los derechos que le asisten". La finalidad de estos preceptos es que la persona detenida -teniendo en cuenta las necesidades derivadas de la situación estresante en la que se halla- comprenda lo que está pasando, las causas y, sobre todo, los derechos de que disfruta. Entre ellos, y a los efectos que nos interesan, destacamos los siguientes:

- Derecho a no declarar contra sí mismo y a no confesarse culpable, lo que implica también el derecho a guardar silencio no declarando si no quiere, a no contestar alguna o algunas de las preguntas que le formulen, o a manifestar que sólo declarará ante el juez.

- Derecho a designar abogado libremente y a solicitar su asistencia en las diligencias que se practiquen, sin demora injustificada. Si la persona detenida no pide un abogado o abogada en concreto, será asistida por una o uno de oficio. En su nueva redacción, la ley detalla en qué consiste la asistencia letrada, lo que supone un importante avance que responde a las exigencias de la UE. Entre las novedades que aquí nos interesan, señalaremos que el letrado o la letrada ha de asegurarse de que la persona detenida ha sido informada y ha comprendido sus derechos, así como la posibilidad de entrevistarse "reservadamente con el detenido, incluso antes de que se le reciba declaración por la policía" (ver nuevo ap. 6 del art. 520 LECrim y Hernández et al. 2015, p. 22). En la misma línea, ahora se reconoce el derecho "a acceder a los elementos de las actuaciones que sean esenciales para impugnar la legalidad de la detención o privación de libertad" (art. 520.2.d) LECrim.). No obstante, el apartado 8 del precepto analizado dice que la persona detenida podrá renunciar a la preceptiva asistencia de abogado si su detención respondiera exclusivamente a posibles delitos contra la seguridad del tráfico.

- Derecho a "que se ponga en conocimiento del familiar o persona que desee, sin demora injustificada, su privación de libertad y el lugar de custodia en que se halle en cada momento". Resulta novedosa la posibilidad de "comunicarse telefónicamente, sin demora injustificada, con un tercero de su elección". Esta comunicación se celebrará en presencia de un funcionario de policía o, en su caso, del funcionario que se designe, pero aun así es un avance, puesto que antes la comunicación la establecía un agente.

- Toda persona detenida tiene derecho a ser reconocida "por el médico forense o su sustituto legal y, en su defecto, por el de la institución en que se 
encuentre, o por cualquier otro dependiente del Estado o de otras Administraciones Públicas".

- Las personas extranjeras tendrán derecho a que las circunstancias anteriores se comuniquen a la oficina consular de su país, así como a ser visitado por dichas autoridades consulares, a comunicarse y a mantener correspondencia con ellas. Además, y en la línea de asegurar la comprensión de los derechos, el apartado 2.h) declara el derecho "a ser asistido gratuitamente por un intérprete, cuando se trate de extranjero que no comprenda o no hable el castellano o la lengua oficial de la actuación de que se trate". Y en respuesta al principio de igualdad material, el mismo derecho se garantiza respecto a personas sordas o con discapacidad auditiva, así como de otras personas con dificultades del lenguaje.

- Conviene insistir, para terminar, en que los anteriores derechos representan un "suelo" mínimo de garantías individuales que no puede vulnerarse, estándar mínimo que es posible tratar de elevar.

\subsection{El contexto institucional: la policía en la Comunidad Autónoma de Euskadi}

Como hemos dicho, son las Fuerzas y Cuerpos de Seguridad del Estado quienes pueden detener, en ejercicio de su función "de proteger el libre ejercicio de los derechos y libertades y garantizar la seguridad ciudadana" (art. 104.1 CE).

A partir de ese reconocimiento constitucional, la Ley Orgánica 2/1986 desarrolla el modelo español de policía, o más bien de policías, ya que regula que las Comunidades Autónomas pueden asumir competencias en materia policial. Tal es el caso de la Comunidad Autónoma de Euskadi, junto con Cataluña y Navarra, mientras que en todo el territorio español están desplegados la Guardia Civil y el Cuerpo de Policía Nacional (CNP), a la vez que en las ciudades de más de diez mil habitantes existen cuerpos de Policía Local (Bergalli 2003, p. 49).

En este sentido, el artículo 17 del Estatuto de Autonomía (Ley Orgánica 3/1979) establece que corresponderá a las instituciones del País Vasco

el régimen de la Policía Autónoma para la protección de las personas y bienes y el mantenimiento del orden público dentro del territorio autónomo, quedando reservados en todo caso a las Fuerzas y Cuerpos de Seguridad del Estado los servicios policiales de carácter extracomunitario y supracomunitario, como la vigilancia de puertos, aeropuertos, costas y fronteras, aduanas, control de entrada y salida en territorio nacional de españoles y extranjeros, régimen general de extranjería, extradición y expulsión, emigración e inmigración, pasaportes y documento nacional de identidad, armas y explosivos, resguardo fiscal del Estado, contrabando y fraude fiscal al Estado.

Frente a este principio general, el apartado 6 del citado artículo 17 recoge algunos supuestos excepcionales en los que los Cuerpos y Fuerzas de Seguridad del Estado podrán intervenir en el mantenimiento del orden público en la Comunidad Autónoma. Todo lo anterior implica que, en la CAE, es la Ertzaintza quien asume la mayoría de las funciones policiales, tanto de protección de la seguridad como de Policía Judicial.

Conviene recordar que, según dispone la ley de Policía del País Vasco (Ley 4/1992) en su artículo 27, los Cuerpos de Policía Local ejercen -entre otras- las siguientes funciones: 
- Proteger a las autoridades de los municipios y vigilancia o custodia de sus edificios e instalaciones.

- Ordenar, señalizar y dirigir el tráfico en el casco urbano, de acuerdo con lo establecido en las normas de circulación.

- Instruir atestados por accidentes de circulación dentro del casco urbano.

- Participar en las funciones de Policía Judicial colaborando con las Unidades de Policía Judicial.

- Efectuar diligencias de prevención y cuantas actuaciones tiendan a evitar la comisión de actos delictivos.

- Vigilar los espacios públicos y colaborar en la protección de las manifestaciones y el mantenimiento del orden en grandes concentraciones humanas, cuando sean requeridos para ello.

En el ejercicio de tales tareas, con frecuencia los agentes municipales realizan detenciones o, en otros casos, citan a las personas para que acudan al juzgado, como imputadas o investigadas, y es desde ese punto de vista que han sido objeto de nuestro estudio.

De esta manera, la CAE experimenta una situación particular de confluencia de Fuerzas y Cuerpos de Seguridad. Dependientes de las administraciones públicas vascas y con la "misión de proteger el libre ejercicio de los derechos y libertades y garantizar la seguridad ciudadana" (Ley 4/1992, art. 4), la Ertzaintza y las policías locales son los principales cuerpos policiales presentes en el territorio. Están también presentes el CNP y la Guardia Civil, que tienen reservados servicios policiales de carácter extracomunitario y supracomunitario, como son la vigilancia de infraestructuras dependientes del Estado, el control de armas y explosivos, o las competencias en extranjería. Por el número de detenciones realizadas en la CAE y por su mayor proximidad con la realidad que queremos estudiar, nos centramos en la experiencia de la Ertzaintza y, en menor medida, de las policías locales de los principales municipios en número de habitantes.

\section{La presencia de las mujeres en las estadísticas policiales y sus perfiles sociodemográficos}

\subsection{Número de mujeres en las estadísticas policiales vascas}

Por cuestiones técnicas y metodológicas nos hemos centrado en cifras proporcionadas por la Ertzaintza primordialmente, cuya matriz de datos recoge las detenciones y las imputaciones practicadas a mujeres durante los años 2011-2016. El cuerpo autonómico registró 4.645 detenidas y 23.405 imputadas, lo que suma un total de 28.050 casos que involucran a mujeres durante este periodo de 6 años.

Si observamos estos datos desde el punto de vista de la situación policial (imputación en general o detención), resulta interesante calcular el peso que tienen las mujeres con respecto de los hombres en cada una de estas categorías. Durante el periodo analizado, las mujeres representaron de media el 10,9\% de las detenciones realizadas por la Ertzaintza, mientras que un $89,1 \%$ correspondió a hombres. En cuanto a las imputaciones, el $24,5 \%$ se ejecutaron a mujeres y un $75,5 \%$ a hombres. Por lo tanto, y si 
consideramos el conjunto de imputaciones, que implican detención o no, que conforman las estadísticas policiales de la Ertzaintza, las mujeres constituyen de media un 20,6\% de los casos registrados durante los años 2011-2016.

\subsection{Delitos objeto de detención e imputación a mujeres en la CAE}

En cuanto a los delitos objeto de imputación, si nos remitimos a los datos de la Ertzaintza, las infracciones contra el patrimonio constituyen el motivo principal que engrosa las estadísticas policiales de mujeres presuntamente responsables, con un 52,4\% de los registros. Le sigue, con un $16,2 \%$ de los casos registrados, una gran categoría de infracciones sin especificar o que no encajan en el resto de categorías. El tercer gran bloque $(14,1 \%)$ lo constituyen las infracciones relacionadas con la violencia en el ámbito familiar, y le siguen las infracciones contra las personas (11,2\%). Para finalizar, las categorías con menos incidencias son las infracciones contra el orden público $(3,6 \%)$ y por conducir bajo la influencia del alcohol y drogas (2,5\%). En el siguiente gráfico se observa la distribución de estas categorías delictivas:

GRÁFICO 1

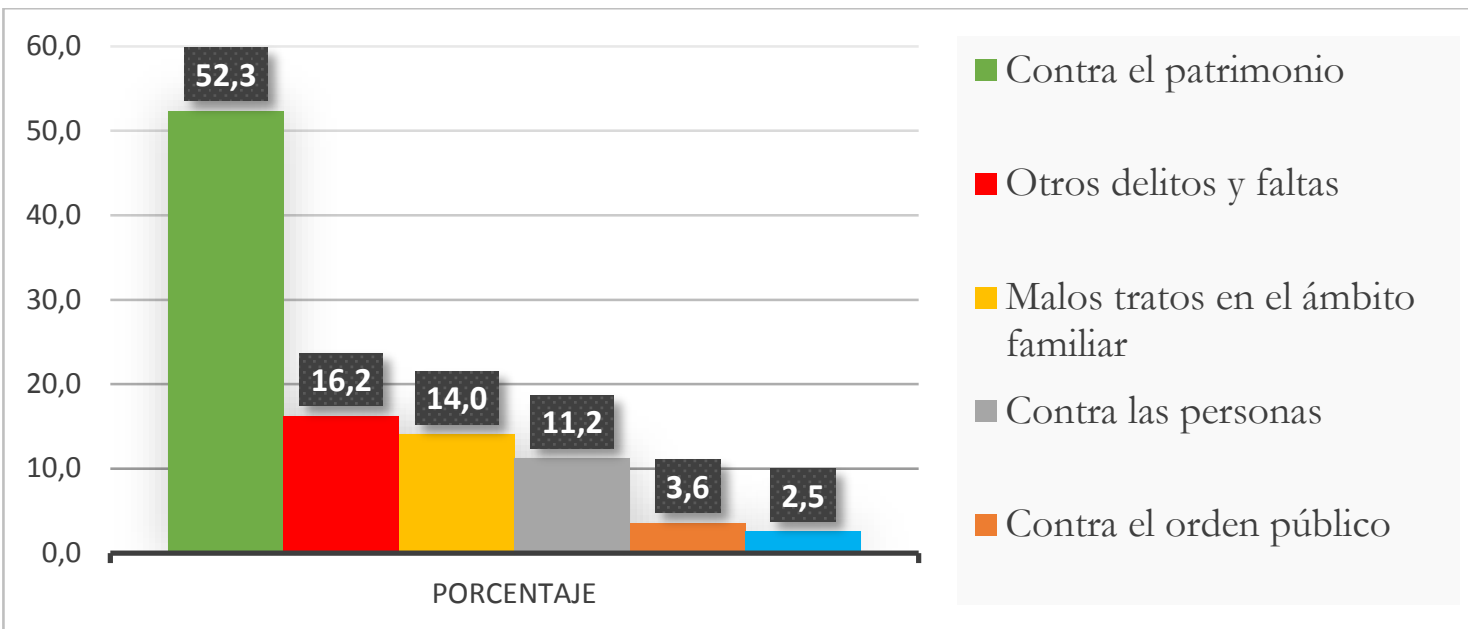

Gráfico 1. Tipo de infracciones que motivan la detención e imputación a mujeres por la Ertzaintza (20112016).

Fuente: elaboración propia a partir de datos de la Ertzaintza.

Dentro de la categoría relativa a infracciones contra el patrimonio, prácticamente tres cuartas partes $(74,8 \%)$ de los casos son hurtos. Dicho de otro modo, el 39,1\% del total de mujeres registradas como detenidas o imputadas por las estadísticas de la Ertzaintza durante los años 2011-2016 lo fueron por hurtos. Las estafas constituyen un 8\% de esta categoría; las diferentes modalidades de robo con fuerza en las cosas suman un 5,6\%; los robos con violencia o intimidación representan un 4,8\%; los daños constituyen un 2,09\%; $\mathrm{y}$, finalmente, quedarían por mencionar otras faltas y delitos contra el patrimonio no especificados $(4,6 \%)$.

La conclusión que puede extraerse del conjunto de datos es que las mujeres acaban imputadas (con o sin detención) principalmente por infracciones leves contra el patrimonio, siendo los hurtos los más habituales. Estas infracciones no tienen un perfil violento, y si acaban detenidas por este motivo generalmente suele ser por no facilitar una identificación o un domicilio habitual. 
La violencia en el ámbito doméstico se sitúa como la segunda categoría delictiva en número de casos (si excluimos la categoría de otros delitos y faltas, compuesta por un número indefinido de infracciones que no podemos precisar). Resulta llamativa la importante presencia de este delito cuando nos referimos a infracciones cometidas por mujeres. Se trata de una cuestión que necesita ser estudiada con mayor detenimiento y que no desarrollaremos en el presente trabajo. Lo que sí podemos matizar es que las estadísticas no informan sobre los miembros de la familia implicados en los hechos, pero de las entrevistas efectuadas tanto a abogados y abogadas como a agentes policiales, se desprende que se trata, en su gran mayoría, de incidentes relacionados con la pareja sentimental.

\subsection{Perfiles de las mujeres detenidas en la CAE}

En lo referente a la posición socioeconómica o la clase social, las estadísticas de la Ertzaintza no arrojan luz sobre esta cuestión. Más específicos han sido los datos facilitados por las policías locales de Durango y Gasteiz para los periodos 2012-2016 y 2011-2016 respectivamente. En el caso de la primera, en un 35,1\% de los 37 atestados relativos a mujeres revisados, el o la agente señala que la detenida o imputada procede de una situación socioeconómica "baja" o introduce elementos que apuntan en esa dirección. Además, un $10 \%$ de las mujeres acusadas por esta policía vivían en la "mendicidad". La Policía Local de Vitoria-Gasteiz, por su parte, recoge información sobre el «nivel cultural» de las personas acusadas que transitan por su comisaría y, entre las 150 mujeres que fueron detenidas en el periodo 2011-2016 (carecemos de esta información respecto de las imputadas), identifican un $70 \%$ de mujeres con un nivel de instrucción "elemental". En un 7,3\% de los casos eran "analfabetas", y sólo un 22,7\% de las mujeres tenían un nivel "medio" (18\%) o "superior" (4,7\%).

Además, la Policía Local de Vitoria-Gasteiz identifica en la mayoría de mujeres detenidas su condición de drogodependiente, siendo un $24,2 \%$ consumidoras habituales y un $7,4 \%$ no adictas pero consumidoras esporádicas. Entre las consumidoras habituales la sustancia más frecuente es el alcohol $(27,8 \%)$, seguido de la cocaína y el hachís o marihuana (22,2\% respectivamente), todas las drogas duras $(13,9 \%)$, la heroína $(11,1 \%)$ y las anfetaminas (2,8\%). Desconocemos si estos datos se obtienen por declaraciones de las detenidas, por la observación del personal policial o por información que éstos puedan disponer.

Los testimonios recogidos por parte de juristas y agentes policiales coinciden en que, salvo circunstancias concretas, se trata de mujeres procedentes de estratos sociales bajos, incluida la cara racializada de la exclusión social, con una alta presencia mujeres de minoría étnica gitana. Nos encontramos ante un perfil -llamémosle así- "tradicional" de la delincuencia, que últimamente se ha visto superado por la presencia de mujeres acusadas por delitos de violencia en el ámbito familiar. Este último tipo no necesariamente responde a un perfil de exclusión o vulnerabilidad social, sino que muchas mujeres de estratos sociales medios se ven involucradas en violencias hacia ascendientes (padre o madre), descendientes (hijos o hijas), pero principalmente hacia la pareja afectiva. Tal y como describe una jurista, "estamos hablando de gente que está en 
situaciones, bueno, pues de necesidad social, exclusión. Luego puede haber alguna que también haya podido (...). Alguna mujer, también, por razones de extranjería" (AB8). ${ }^{3}$

\subsection{Procedencia geográfica-nacionalidad}

En cuanto al lugar de nacimiento, y centrándonos en las estadísticas de la Ertzaintza para los años 2011-2016, observamos que el 53,2\% de las mujeres detenidas o imputadas habían nacido en la CAE, un 15,4\% en el resto de provincias del Estado y el 31,4\% lo hicieron en un país extranjero. Es evidente que las mujeres extranjeras están claramente sobrerrepresentadas en las estadísticas policiales en relación con la presencia que tienen en el conjunto de la población femenina de la CAE. Las mujeres nacidas fuera del Estado constituyeron un $29,92 \%$ del conjunto de las detenidas e imputadas por la Ertzaintza durante los años 2015-2016, mientras que su peso en el total de mujeres residentes en el territorio era del $8,65 \% .^{4}$

Si atendemos a las regiones de origen, del total de extranjeras detenidas o imputadas por la Ertzaintza casi la mitad (48,1\%) habían nacido en un país de América Latina; un 24,3\% eran originarias de Europa del Este; ${ }^{5}$ un 9,5\% nacieron en el Magreb (Marruecos, Sáhara, Argelia, Mauritania, Libia y Túnez); ${ }^{6}$ un $7,8 \%$ lo hicieron en el resto del territorio africano; un 6,8\%, en Europa Occidental; y el 3,5\% restante en algún país de Asia, Oceanía, Norteamérica u otros. Estos datos se correlacionan con el porcentaje de mujeres que viven en la CAE según su lugar de nacimiento.

Todo esto evidencia la selección del sistema penal orientada a colectivos desfavorecidos. Se trata, por un lado, de la intersección que se produce entre género, clase social o estrato socioeconómico bajo, rasgos o procedencia étnica y diversos ejes de exclusión social. Y por otro, de cuestiones de género que se cruzan con conflictos en el ámbito íntimo, entre los que se encuentran la violencia machista y sus consecuencias para las mujeres.

\section{El proceso de la detención. Cumplimiento de derechos formales, con matices}

Las mujeres participantes en el estudio que han pasado por una experiencia de detención han sido nueve. Casi todas las protagonistas son de grupo étnico mayoritario, esto es, blancas, y casi todas de nacionalidad española salvo dos extranjeras: una comunitaria y

\footnotetext{
${ }^{3}$ Para garantizar el anonimato, a cada persona entrevistada se le ha asignado un código de identificación, que se especifica al final de cada frase o relato proporcionado. Las voces de las mujeres que han pasado por una experiencia de detención han sido codificadas con una " $\mathrm{D}$ " más un número. Las y los profesionales de

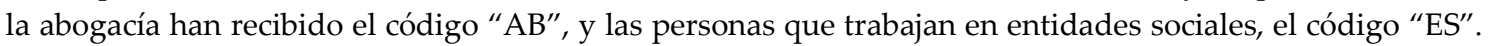
Finalmente, el personal policial ha sido identificado mediante una " $\mathrm{P}$ ", seguida de una " $\mathrm{M}$ " si se trata de una mujer y una " $\mathrm{H}^{\prime}$ en el caso de un hombre.

${ }^{4}$ Datos calculados a partir de cifras de Eustat (a 1 de enero de cada año), de Ikuspegi (Observatorio Vasco de Inmigración) y de la Ertzaintza. Los datos se refieren a los años 2015-2016, porque mientras la Ertzaintza trabaja con la variable lugar de nacimiento, Ikuspegi recogía hasta el año 2014 información relativa a la nacionalidad de las personas, divergencia que distorsiona sustantivamente los resultados.

${ }^{5}$ Tomando como referencia Naciones Unidas se han incluido: Albania, Armenia, Azerbaiyán, Bielorrusia, Bosnia-Herzegovina, Bulgaria, Croacia, Eslovaquia, Estonia, Macedonia, Georgia, Hungría, Letonia, Lituania, Montenegro, Polonia, República Checa, Moldavia, Rumanía, Rusia, Serbia y Ucrania. Véase: http://www.un.org/es/hq/dgacm/regionalgrps.shtml

${ }^{6}$ Son los países ampliamente aceptados como el Magreb. Véase, por ejemplo: http://entrefronteras.com/quees-el-magreb/
} 
otra latinoamericana. Casi todas han sido detenidas por la Ertzaintza, aunque alguna de ellas, al ser detenida más de una vez, también lo fue por la policía local. Existe un caso cuyas circunstancias y experiencia en detención varían considerablemente respecto a las demás, y es el de una mujer extranjera detenida por la Guardia Civil. Los delitos por los que han sido acusadas son (por orden de presencia): contra la salud pública, contra la propiedad, lesiones y enaltecimiento del terrorismo y desobediencia civil. Todas ellas estuvieron en situación de detención ordinaria, no incomunicada y, en la mayoría de los casos, menos de 24 horas.

De manera general, las mujeres detenidas, abogados y abogadas, y agentes policiales entrevistadas para nuestra investigación manifiestan que se han respetado los derechos formales que les asisten como detenidas (asistencia letrada, asistencia médica, cacheo por parte de una mujer, etc.) y que no han padecido malos tratos físicos o sexuales. No obstante, ciertas actitudes hoscas en el trato han sido destacadas por varias mujeres detenidas. Una de ellas lo nombra, precisamente, como maltrato psicológico, al describir las formas verbales que usaron con ella en el trayecto a comisaría y en el interrogatorio:

Digamos que, como yo, para el delito que estaba, pues se creían jueces ellos, te despreciaban, te hacían sentir que no eras nada. Sobre todo, como si ellos fuesen jueces. Ellos están para hacer cumplir la Constitución, a mí ya me juzgarán y verán si soy culpable o no, pero ellos no son jueces, son policías. Muchas veces te ves humillada moralmente, o con su actitud, la actitud no verbal que tenemos las personas. (D5)

Las actitudes negativas manifestadas por algunas participantes que han vivido una detención tienen que ver con esa rudeza en el trato. En lo que respecta a otras acciones preceptivas, como que les informen de sus derechos, reciban asistencia médica si lo solicitan, intérprete en caso necesario, cacheo por parte de una mujer y alimentación adecuada, se suele cumplir. Aunque las personas que trabajan en entidades sociales coinciden en reconocer que en comisaría se respetan los derechos básicos de las personas, como la asistencia letrada o médica, un integrante de una organización social apunta matices en lo referente a los procedimientos relacionados con la asistencia de intérpretes:

El tema del intérprete, dependiendo de la generalidad, se respeta menos o más. O se recurre a personas que no son intérpretes profesionales. Sobre todo, en el momento de comisaría se suele recurrir más a otro detenido que sabe el idioma, o que es de la misma nacionalidad, o sabe castellano, o cosas por el estilo. En el juzgado cambia. Allí suele respetarse más el tema del intérprete, pero en comisaría, muchas veces, sobre todo en detenciones breves, pues aceleran un poco la puesta a disposición judicial para no tener que recurrir al intérprete y pueden saltarse alguna situación. No te hablo específicamente de mujeres, sino de las detenciones en general. (ES2)

En esta línea, la misma urgencia de querer finalizar con el proceso cuanto antes puede provocar que las personas detenidas renuncien a determinados derechos: "Tienen derecho a tener abogado en euskera, pero como suelen tardar mucho en venir, 'vale, vamos a declarar cuanto antes, que yo me quiero marchar'" (AB4).

Lo mismo sucede cuando las detenidas valoran que la posibilidad de solicitar asistencia médica puede prolongar su proceso de detención. Por lo tanto, este derecho se ve fuertemente condicionado, tal y como comentó una abogada:

Tú tienes un derecho, que es a que te vea un médico. Las que han delinquido más veces, o las que han estado (...) ya lo saben. Cuanto más pidas eso, más tarde sales. Porque 
claro, sales durante el tiempo en el que estás detenida. Entonces vas al hospital custodiada, escoltada, vuelves y más tiempo tardas, claro. Entonces, la gente renuncia a ese derecho, aunque esté con la pata colgando. O que le hayan pegado. $\mathrm{O}$ aunque le hayan... Yo qué sé. Sí. Lo que quieres es salir cuanto antes. (AB11)

Una participante detenida, de hecho, manifiesta que rehusó a que le llevaran al médico, a pesar de padecer dolores de cabeza y de que los agentes le insistieran:

Yo dije que no, que al médico no iba porque en los traslados te llevan esposada, te sacan esposada en el médico, en el hospital, pues la verdad es que no me apetecía nada revivir un traslado otra vez. (D1)

Una abogada realiza otra apreciación que merece ser considerada, cuando advierte que el nivel de instrucción de las personas que pasan por comisaría provoca, en muchos casos, dificultades de comprensión en la lectura de derechos, al no tener en cuenta que:

La gente desconoce la terminología, todo se le dice súper rápidamente. Que le dicen: 'usted tiene derecho, bla, bla [habla muy rápido]'. ¿Qué va a entender? No ha entendido nada. Creo que hay cosas que se pueden hacer en lenguaje más comprensible y dedicarle más atención. La gente está en una situación que no es normal. (AB4)

Preguntar posteriormente a la persona implicada si ha comprendido o no lo que muchas veces se ha podido decir de forma automática, no siempre es suficiente para asegurar que así ha sido. En este sentido, una abogada procedente de una entidad social ilustra con claridad la situación en la que encuentra a algunas detenidas atendidas:

Algunas están, 'qué ha pasado, por qué estoy aquí, qué coño está pasando'. Obvio, y lo ves. Te das cuenta de que no se está enterando de nada de lo que está pasando. Pero luego ya con tranquilidad se lo explicas. Haces un croquis o lo que sea. (AB14)

La asistencia letrada casi siempre es rápida en acudir a comisaría, y concuerdan también con que el tiempo de detención es corto, salvo circunstancias especiales. Generalmente, pasan en comisaría unas horas, si son detenidas durante el día, o una noche si son aprehendidas después de las 5 de la tarde, que es cuando acaba el turno del juzgado.

Las medidas de seguridad son las mismas para hombres y para mujeres, a excepción del momento del cacheo, que debe realizarse por una persona del mismo sexo, algo que se respeta escrupulosamente, tal y como confirman las diferentes partes participantes en la investigación.

No obstante, la situación de especial vulnerabilidad propia de algunos casos pone en cuestión la escrupulosa igualdad en la realización del cacheo. Algunas agentes policiales traen a la conversación una experiencia que tuvieron que resolver, no sin dificultades y con cierta improvisación. Se trataba de una mujer paquistaní con tres hijos que hablaba poco inglés, con la que tuvieron dificultades para encontrar un intérprete que hablara el urdu, su lengua materna: "La chica estaba muy, muy nerviosa, y era una requisitoria. $\mathrm{O}$ sea, no era nada grave que hubiera pasado, sino una requisitoria judicial. [Estaba muy nerviosa] Porque no sabía lo que pasaba" (PM8). Su compañera continúa:

Hombre, nos vimos en una situación diferenciada, que tuvimos que..., no improvisar, sino cambiar un poco el proceso de la detención. Se notaba que la mujer estaba bastante asustada y se le explicó cómo se iba a... qué es lo que se tenía que hacer en cuanto a lo corporal, sus derechos y tal. Y claro, para ella fue... Por ejemplo, lo vivió de una forma... Bueno, lloraba la mujer porque estaba bastante mal, el tema del cacheo. Entonces, pues 
se decidió no hacerle un cacheo exhaustivo, digamos. Al final, es por seguridad para los agentes y por seguridad para ellos mismos. Entonces en ese caso, al final optamos por no hacerle un cacheo exhaustivo porque, claro, lo poco que podíamos entender decía 'mi marido, mi marido, mi marido'. ¡Fíjate! Esta mujer, su religión, que iba toda tapada con el sari, pues, a ver, era por un delito de una estafa. Quiero decir, si hubiera sido porque es una persona agresiva o por otro tipo de delito, pues por su seguridad y por la nuestra tendríamos que haberlo hecho, pero intentas adaptarte un poquito a la situación. (PM9)

En vista de lo sucedido, cabe subrayar la pertinencia de mirar en clave interseccional y saber adaptar los procedimientos a las circunstancias y condiciones de las personas en cada situación. Existe una circunstancia adicional que un responsable de la Ertzaintza reconoce no saber cómo abordar a la hora de elegir qué agente, mujer u hombre, debe cachear a las personas transexuales:

Es muy complicado porque cuando ellas tienen hecha una operación de sexo pues no hay ninguna dificultad, son mujeres a todos los efectos. Lo que ocurre es que con travestis y con personas que aún no han hecho la reasignación de sexo, entonces, obviamente a nuestras propias compañeras no les podemos pedir que... Sí, a ellas [a las personas transexuales se les pregunta], ellas pueden preferir una mujer, pero si tienen genitales masculinos nuestras compañeras no quieren, claro. (RE1)

El entrevistado señala contradicciones entre la voluntad que pueden explicitar las mujeres transexuales que no han culminado el proceso de reasignación de sexo (prescrito médica y jurídicamente) de que les cachee una mujer, y las reservas por parte de las agentes si consideran que acceder supone no cumplir con los protocolos establecidos, lo que posteriormente puede causarles problemas.

\section{Conclusiones}

La presente investigación sociológica sobre la experiencia de detención policial a mujeres en la CAE abre una vía de estudio prácticamente inexplorada en el ámbito vasco, estatal e internacional. Los resultados de la investigación suponen un aporte al conocimiento del panorama penal vasco, pero también contribuyen al debate en contextos más amplios y a la sociología jurídica en general. Centrarnos en el estado inicial del proceso de selección penal, antes de la entrada en prisión de determinadas mujeres, nos permite comprender el sistema penal como un continuo en el que entran en juego una variedad de agentes, códigos y enfoques, todos ellos más o menos empapados de una perspectiva androcéntrica que predomina en el conjunto de nuestra sociedad.

Muchas de las cuestiones que han emergido pueden aplicarse perfectamente al caso de los hombres también, pero atender de forma específica la experiencia del género implica visibilizar una de las principales categorías de desigualdad y discriminación social que existen en nuestra sociedad. Siendo la sociedad de manera general de corte patriarcal (en la que se entrecruzan otros ejes de desigualdad), lo que aquí interesa es comprender de qué manera específica el orden de género (junto con otros como el de clase social, o procedencia étnica y geográfica) está condicionando la experiencia de detención de las mujeres y las prácticas de la institución policial.

Las estadísticas policiales registradas por la Ertzaintza evidencian que las mujeres representaron de media un 10,9\% frente al $89,1 \%$ de hombres del total de personas detenidas en los últimos años. Este resultado coincide con los datos proporcionados por 
las policías locales para nuestra investigación y con lo destacado por la literatura criminológica internacional, constatando así que la proporción de mujeres en las estadísticas de la CAE es similar a la que reflejan los estudios sobre delincuencia perpetrada por mujeres. Por tanto, las mujeres representan en relación con los hombres una proporción pequeña, pero no desdeñable, de las detenciones e imputaciones practicadas por las policías.

Más allá de saber cuántas mujeres forman parte de los registros policiales, nos ha interesado conocer qué delitos han cometido y quiénes son, es decir, cuáles son sus perfiles sociodemográficos. El tipo de infracción que principalmente motiva la detención o imputación de mujeres por parte de la Ertzaintza es, en la mitad de los casos, el delito contra el patrimonio (52,4\%), constituyendo los hurtos tres cuartas partes de los casos de esta categoría.

Sobre el perfil sociodemográfico de las detenidas, los discursos de los y las profesionales son confluyentes a la hora de afirmar que, salvo circunstancias concretas, provienen de estratos sociales bajos, lo cual se encuentra en la línea de los estudios criminológicos y concuerda con las teorías críticas que describen los procesos de selección penal de las personas empobrecidas. Se trata de mujeres que habitualmente proceden de contextos de exclusión social, con importante presencia de mujeres racializadas y, al parecer, con una notable representación de mujeres de etnia gitana. Todo indica que los ejes de clase social (baja), etnia (minoritaria, gitana) y procedencia geográfica (extranjera) están incidiendo en mayor o menor medida en la configuración de las cifras de la presunta delincuencia interceptada por la policía, unos rasgos que no necesariamente responden al hecho de que estos sectores delincan más, sino a la orientación del proceso de selección penal, como hemos venido insistiendo.

Por otro lado, estos rasgos tienen unas implicaciones directas en la vivencia de la detención que es necesario tener en cuenta, ya que no sólo se trata de introducir la variable género para entender la experiencia de detención policial de las mujeres, sino que también es necesario atender otros ejes en juego que conforman una variabilidad de experiencias que requieren análisis específicos.

No se reportan cuestiones relevantes en relación con las garantías legales en el proceso de la detención, salvo algunos apuntes concretos que afectan a la forma como se ponen en práctica. El procedimiento, que incluye leer los derechos, proporcionar asistencia letrada, intérprete si lo necesitase, asistencia médica si lo solicita, alimentación o cacheo por parte de una mujer, parece llevarse a cabo correctamente. El aspecto más débil es el de proporcionar «información comprensible» sobre los hechos que han causado la detención, sobre los derechos exigibles, etc. y la cuestión del cacheo en caso de personas transexuales sin reasignación de sexo o aquellas que por cuestiones religiosas o culturales tienen dificultades con que personas extrañas examinen su cuerpo.

Hemos encontrado consenso profesional respecto a que la duración de la detención debe prolongarse lo menos posible, $\mathrm{y}$, de hecho, habitualmente no excede de las 24 horas. El deseo de evitar dilataciones de tiempo provoca, en ocasiones, que las detenidas renuncien a sus derechos, como por ejemplo de asistencia en euskera o de asistencia médica. 
De manera general, por tanto, las diferentes instancias implicadas en el proceso de detención, incluidas las mujeres detenidas, manifiestan que se han respetado los derechos formales y que no han padecido malos tratos físicos o sexuales. La cuestión del maltrato psicológico tampoco ha sido reportado de manera habitual, pero resulta necesario hacer unas consideraciones a este respecto, ya que nos movemos en un terreno lleno de matices y en un contexto, el de la detención, que de por sí constituye un entorno estresante.

\section{Referencias}

Almeda, E., Di Nella, D., y Navarro, C., 2012. Mujeres, cárceles y drogas: datos y reflexiones. Oñati Socio-Legal Series [en línea], 2(6), 122-145. Disponible en: http://papers.ssrn.com/sol3/papers.cfm?abstract id=2115434 [Con acceso el 25 de marzo de 2019].

Antón-Mellón, J., y Antón Carbonell, E., 2017. Populismo punitivo, opinión pública y leyes penales en España (1995-2016). Revista Internacional de Pensamiento Político [en línea], vol. 12, 133-150. Disponible en:

http://rabida.uhu.es/dspace/bitstream/handle/10272/14958/Populismo.pdf?sequen ce=2 [Con acceso el 25 de marzo de 2019].

Argituz Asociación pro derechos humanos, 2012. Necesidades, obstáculos y buenas prácticas en los itinerarios de salida de la violencia de género desde la experiencia de mujeres en el área rural de Araba [en línea]. Vitoria-Gasteiz: Emakunde. Disponible en:

http://www.bizkaia.eus/gizartekintza/Genero Indarkeria/blt28/documentos/arab a_c.pdf?hash=4a9634e5ae828546d1adac336c540115 [Con acceso el 25 de marzo de 2019].

Armenta, T., 2010. Lecciones de Derecho Penal. Madrid: Marcial Pons.

Beltrán, M.A., 2010. Criminología feminista: Estado del arte y presencia en Latinoamérica [en línea]. VI Jornadas de Sociología de la UNLP2. La Plata, 9 y 10 de junio. En Memoria Académica. Disponible en:

http://www.memoria.fahce.unlp.edu.ar/trab eventos/ev.5515/ev.5515.pdf [Con acceso el 25 de marzo de 2019].

Bergalli, R., 2003. Las funciones del sistema penal en el estado constitucional de derecho, social y democrático: perspectivas socio-jurídicas. En: R. Bergalli, ed., Sistema penal y problemas sociales. Valencia: Tirant lo Blanch, 25-82.

Blay Gil, E., 2013. “Voy o no voy": el recurso a la policía en el caso de la violencia de género. Perspectivas de las víctimas. Estudios Penales y Criminológicos [en línea], 33, 369-400. Disponible en:

http://www.usc.es/revistas/index.php/epc/article/view/1502/1666 [Con acceso el 25 de marzo de 2019].

Bottero, W., 2005. Stratification: Social Division and Inequality. Londres: Routledge.

Canteras Murillo, A., 1990. Delincuencia femenina en España. Madrid: Ministerio de Justicia. 
Chesney-Lind, M., 2006. Patriarchy, Crime, and Justice: Feminist Criminology in an Era of Backlash. Feminist Criminology [en línea], 1(1), 6-26.

https://doi.org/10.1177/1557085105282893 [Con acceso el 25 de marzo de 2019].

Combahee River Collective, 2012. Un manifiesto feminista Negro. En: R.L. Platero, ed., Intersecciones: Cuerpos y sexualidades en la encrucijada. Barcelona: Bellaterra, 75-86.

Comité para la Prevención de la Tortura, 2017. Informe para el Gobierno Español sobre la visita llevada a cabo en España por el Comité Europeo para la Prevención de la Tortura y de las penas y tratos inhumanos o degradantes (CPT/Inf (2017) 34) [en línea]. Estrasburgo: Consejo de Europa. Disponible en: https://rm.coe.int/pdf/168076696c [Con acceso el 25 de marzo de 2019].

Crenshaw, K.W., 2012. Cartografiando los márgenes. Interseccionalidad, políticas identitarias y violencia contra las mujeres de color. En: R.L. Platero, ed., Intersecciones: Cuerpos y sexualidades en la encrucijada. Barcelona: Bellaterra, 87-122.

Cruells, M., y Torrens, M., 2004. Mujeres, integración y prisión: Informe Nacional España. Barcelona: Surt.

De Miguel Calvo, E., 2015. Mujeres usuarias de drogas en prisión. Praxis Sociológica, 19, 141-59.

De Miguel Calvo, E., 2016. Mujeres, consumo de drogas y encarcelamiento. Una aproximación interseccional. Política y Sociedad [en línea], 53(2), 529-49.

Disponible en: https://doi.org/10.5209/rev POSO.2016.v53.n2.47421 [Con acceso el 25 de marzo de 2019].

Díez Ripollés, J.L., 2015. Delitos y penas en España. Madrid: Catarata.

Dirección de Atención a las Víctimas de Violencia de Género, 2012. Mujeres víctimas de violencia de género: Vivencias y demandas [en línea]. Vitoria-Gasteiz: Servicio Central de Publicaciones del Gobierno Vasco. Disponible en:

https://www.emakunde.euskadi.eus/contenidos/informacion/violencia guias/es def/adjuntos/pub.mujeres.victimas.de.violencia.cas.pdf [Con acceso el 25 de marzo de 2019].

Draminsky Petersen, H., y Morentin, B., 2017. Detainees' perception of the doctors and the medical institution in Spanish police stations: An impediment in the fight against torture and ill-treatment. Torture Journal [en línea], 27(2). Disponible en: https://doi.org/10.7146/torture.v27i2.97217 [Con acceso el 25 de marzo de 2019].

Emakunde, 2015. Becas de trabajos de investigación en materia de igualdad de mujeres y hombres para el año 2016 [en línea]. Vitoria-Gasteiz: Gobierno Vasco. Disponible en: https://www.euskadi.eus/web01-

tramite/es/contenidos/ayuda subvencion/becas 2016/es def/index.shtml [Con acceso el 25 de marzo de 2019].

Equipo Barañí, 2001. Mujeres gitanas y sistema penal. Madrid: METYEL.

Etxeberria, F., Beristain, C.M., y Pego, L., 2016. Proyecto de investigación de la tortura en el País Vasco (1960-2013) [en línea]. Por encargo de la Secretaría General para la Paz y la Convivencia. Vitoria-Gasteiz: Gobierno Vasco. Disponible en: 
http://www.eitb.eus/multimedia/documentos/2016/06/27/1987310/Memoria Proyecto tortura 2016.pdf [Con acceso el 25 de marzo de 2019].

Gandarias Goikoetxea, I., 2017. ¿Un neologismo a la moda?: Repensar la interseccionalidad como herramienta para la articulación política feminista. Investigaciones Feministas [en línea], 8(1), 73-93. Disponible en: https://doi.org/10.5209/INFE.54498 [Con acceso el 25 de marzo de 2019].

Gañan, A., y Gordon, B., 2001. La mujer drogodependiente penada en los centros penitenciarios [en línea]. Madrid: Asociación Servicio Interdisciplinar de Atención a las Drogodependencias (SIAD). Disponible en: http://www.drogasextremadura.com/archivos/La-mujer-drogodependientepenada-en-los-C.-P..pdf [Con acceso el 25 de marzo de 2019].

Gelsthorpe, L., y Morris, A., 1990. Introduction: transforming and transgressing criminology. En: L. Gelsthorpe y A. Morris, eds., Feminist Perspectives in Criminology. Milton Keynes-Philadelphia: Open University Press, pp. 1-6.

Heimer, K., y Kruttschnitt, C., 2005. Gender and Crime: Patterns in Victimization and Offending. New York University Press.

Hernández, C., et al., 2015. Guía antirrepresiva: Derechos y libertades para la lucha social. Bilbao: DDT Banaketak / Sare Antifascista.

Imaz, E., y Martín-Palomo, T., 2007. Las otras otras: extranjeras y gitanas en las cárceles españolas. En: B. Biglia y C. San Martín, eds., Estado de Wonderbra: Entretejiendo narraciones feministas sobre las violencias de género. Madrid: Virus, 217-227.

Larrauri, E., 1992. La herencia de la criminología crítica. Madrid: Siglo XXI.

Manzanos, C., 1991. Cárcel y marginación social: Contribución crítica e investigación aplicada a la sociedad vasca. San Sebastián-Donostia: Gakoa.

Maqueda, M.L., 2014. Razones y sinrazones para una criminología feminista. Madrid: Dykinson.

Markez, I., y Silvosa, G., 2012. Drogas y género en el ámbito penitenciario. Oñati SocioLegal Series [en línea], 2(6), 146-160. Disponible en: http://opo.iisj.net/index.php/osls/article/view/146 [Con acceso el 25 de marzo de 2019].

Martín-Palomo, M.T., Miranda, M.J., y Vega, C., eds., 2005. Delitos y fronteras: Mujeres extranjeras en prisión. Madrid: Instituto de Investigaciones Feministas / Editorial Complutense.

Miranda, M.J., y Martín-Palomo, T., 2007. Mujeres no nacionales en prisión. En: E. Almeda y E. Bodelón, eds., Mujeres y castigo: Un enfoque socio-jurídico y de género. Madrid: Dykinson, 187-210.

Platero, R.L., 2014. Metáforas y articulaciones para una pedagogía crítica sobre la interseccionalidad. Quaderns de Psicología [en línea], 16(1), 55-72. Disponible en: http://doi.org/10.5565/rev/qpsicologia.1219 [Con acceso el 25 de marzo de 2019]. 
Restrepo, D., y Francés, P., 2016. Rasgos comunes entre el poder punitivo y el poder patriarcal. Revista Colombiana de Sociología [en línea], 39(1), 21-46. Disponible en: https://doi.org/10.15446/rcs.v39n1.56340 [Con acceso el 25 de marzo de 2019].

Ribas, N., Almeda, E., y Bodelón, E., 2005. Rastreando lo invisible: Mujeres extranjeras en las cárceles. Barcelona: Anthropos.

Ribas, N., y Martínez, A., 2003. Mujeres extranjeras en las cárceles españolas. Revista Sociedad y Economía [en línea], 5, 65-80. Disponible en:

http://www.redalyc.org/articulo.oa?id=99617828003 [Con acceso el 25 de marzo de 2019].

Rice, M., 1990. Challenging orthodoxies in feminist theory: a black feminist critique. En: L. Gelsthorpe y A. Morris, eds., Feminist Perspectives in Criminology. Milton Keynes-Philadelphia: Open University Press, 57-69.

Segovia, J.L., 2011. Código Penal a tu alcance. Madrid: Popular.

Smart, C., 1977. Women, Crime and Criminology: A Feminist Critique. Londres: Routledge \& Kegan Paul.

Sutherland, E.H., 1999. El delito de cuello blanco. Madrid: La Piqueta.

Walmsley, R., 2015. World Female Imprisonment List, $3^{\text {rd }}$ Edition [en línea]. Londres:

World Prison Brief / Institute for Criminal Policy Research. Disponible en:

http://www.prisonstudies.org/sites/default/files/resources/downloads/world fem ale imprisonment list third edition 0.pdf [Con acceso el 25 de marzo de 2019].

Zuloaga, L., 2014. El espejismo de la seguridad ciudadana: Claves de su presencia en la agenda política. Madrid: Catarata.

\section{Referencias normativas}

Constitución Española, 29 de diciembre de 1978.

Declaración de Viena sobre la delincuencia y la justicia: frente a los retos del siglo XXI

(RES/55/59) [en línea]. Organización de las Naciones Unidas, 4 de diciembre de 2000. Disponible en:

http://biblioteca.cejamericas.org/bitstream/handle/2015/4336/onu-declaracionviena.pdf?sequence=1\&isAllowed=y [Con acceso el 25 de marzo de 2019].

Ley 4/1992, de 17 de julio, de Policía del País Vasco.

Ley Orgánica 13/2015, de 5 de octubre, de modificación de la Ley de Enjuiciamiento

Criminal para el fortalecimiento de las garantías procesales y la regulación de las medidas de investigación tecnológica.

Ley Orgánica 2/1986, de 13 marzo, de Fuerzas y Cuerpos de Seguridad.

Ley Orgánica 3/1979, de 18 de diciembre, de Estatuto de Autonomía para el País Vasco.

Reglas de Bangkok: Reglas de las Naciones Unidas para el tratamiento de las reclusas y medidas no privativas de la libertad para las mujeres delincuentes y sus Comentarios (A/RES/65/229) [en línea]. Viena: Oficina de las Naciones Unidas contra la Droga y el Delito, 16 de marzo de 2011. Disponible en: 
https://www.unodc.org/documents/justice-and-prison-

reform/Bangkok Rules ESP 24032015.pdf [Con acceso el 25 de marzo de 2019]. 